\title{
As faces (in)visíveis da regeneração urbana: rua Riachuelo e a produção de um cenário gentrificado
}

The (in)visible faces of urban regeneration: Riachuelo Street and the production of a gentrified scenario

Andrei Mikhail Zaiatz Crestani

\section{Resumo}

Projetos de recuperação de centros urbanos vêm se apresentando como importante campo de investigação. Existe uma preocupação em interpretar os deslocamentos de significados urbanos e as consequências da silenciosa substituição social e cultural que vêm naturalizando o enobrecimento como estratégia de gestão da imagem da cidade. Neste trabalho, analisa-se o projeto "Novo Centro" de Curitiba focando especificamente as transformações da Rua Riachuelo desde 2009. São exploradas as contribuições de Hamnnet (2003), Smith (2002; 2006), Vargas e Castilho (2009), entre outros teóricos. Em uma paisagem ainda não totalmente transformada, a Riachuelo tem impactos sensíveis, ainda que não totalmente visíveis, de um processo em que a gentrificação é tida como instrumento de política urbana que subsidia sua remodelagem socioespacial, cultural e econômica.

Palavras-chave: gentrificação; Rua Riachuelo; regeneração urbana.

\begin{abstract}
Urban regeneration projects have become an important research field. There is a concern about interpreting the displacement of urban meanings and the consequences of a silent social and cultural substitution, which have been naturalizing urban ennoblement as a strategy to manage the city's image. In this paper, the project "New Center", developed in the city of Curitiba (Southern Brazil) is analyzed, focusing specifically on changes that have been occurring in Riachuelo Street since 2009. Contributions from Hamnnet (2003), Smith (2002; 2006), Vargas and Castillo (2009), among others, are explored. In a scenario that has not been completely remade, Riachuelo Street presents sensitive impacts, although they are not fully visible, from a process in which gentrification is used as an urban policy instrument that supports sociospatial, cultural and economic remodeling.
\end{abstract}

Keywords: gentrification; Riachuelo Street; urban regeneration 


\section{Introdução}

Projetos urbanos de revitalização, requalificação, reestruturação ou renovação têm obtido um importante espaço na agenda de pesquisas científicas que buscam interpretar os mecanismos de alteração da imagem da cidade e do conteúdo que a significa. Paralelamente, tais categorias de intervenção permanecem na pauta da gestão pública que, constantemente, investe em transformações estratégicas de determinadas áreas da cidade que implicam substancialmente a manutenção de suas dinâmicas socioespaciais e das economias locais que a elas se relacionam.

Determinados processos frequentemente são localizados em áreas centrais abandonadas ou degradadas que conformam importante cenário das relações históricas, sociais, infraestruturais, econômicas e de imagem da cidade e, portanto, são recorrentemente espaços de interesse de atores públicos e privados pela expectativa de capitalização do investimento que são capazes de gerar.

Com vista à projeção de sucesso - principalmente econômico e a partir - dos investimentos na transformação da imagem da cidade, narrativas midiáticas e políticas coadunam em um discurso de emergência na renovação, recuperação, reabilitação, etc.

Associado a tais movimentos de gestão da cidade está o fenômeno da gentrificação. A gentrificação pressupõe transformações de centros urbanos em suas dimensões materiais, econômicas, sociais e simbólicas (Zachariasen, 2006), bem como uma reconfiguração da economia local no contexto no qual se manifesta, designando um processo de deslocamento de um grupo social participante das classes populares do centro (Smith, 2006) e o enobrecimento dessas áreas antes degradadas (Vargas e Castilho, 2009).

Especialmente nas décadas de 1980 e 1990, o retorno dos grandes projetos de intervenção urbana, em diversos contextos mundiais, foi pano de fundo para diversos estudos preocupados em interpretar processos e legados da gentrificação. No cenário científico, autores como Harvey (1989), Parkinson (1990) e Robson (1994) revelaram as diferentes faces desse fenômeno em que existe uma tendência dos benefícios sociais serem endereçados aos agentes privados, tais como: proprietários de terra e empreendedores imobiliários, enquanto a população residente das áreas modificadas permaneceria longe de suprir suas demandas como emprego, melhoria das condições de moradia e serviços em geral.

0 fenômeno manifesta-se de modo específico de local para local (Smith, 2006), sendo necessárias investigações específicas com o intuito de mapear suas variações e proporcionar interpretações a partir de casos que, ainda geograficamente localizados, se conectam por uma lógica global de produção da cidade contemporânea.

Este trabalho analisa o recente projeto em andamento de renovação do centro histórico de Curitiba, tendo como objeto específico a Rua Riachuelo e as ações relativas a sua transformação, bem como seus efeitos sensíveis ainda que, por vezes, invisíveis. 0 objetivo é avaliar como os projetos desse contexto são articulados entre poder público e privado, qual o reflexo socioespacial e econômico que esse movimento tem resultado e sua relação com indícios da construção de um cenário de gentrificação. 


\section{Renovação dos centros urbanos e a gentrificação}

Desde as primeiras reflexões de Glass sobre a gentrificação, em um contexto pós revolução industrial quando a cidade aspirava a uma realidade desenvolvimentista, o fenômeno vem sido estudado junto à dinâmica de produção da cidade e, portanto, tem contornos conceituais ajustáveis aos diferentes processos de configuração do ambiente urbano.

A partir de uma perspectiva da geografia, Hamnett (2003), somando as considerações de Ley e Butler, encontra na modificação da estrutura de produção industrial seu argumento sobre o ponto fundante da gentrificação: a substituição da estrutura da classe trabalhadora por um significativo contingente de profissionais de "colarinho branco", os quais têm nas grandes cidades a base de suas finanças, cultura e trabalho. Tais mudanças na composição da classe trabalhadora culminariam em determinada atualização do perfil cultural que, por distintas preferências e rotina de trabalho, apresentaria uma predisposição na busca do centro da cidade como espaço do habitat.

Contrariamente à perspectiva de que a gentrificação se associava a uma característica específica de um grupo social que procurava ocupar determinadas áreas da cidade, Smith (2002), em uma abordagem crítica marxista (Mendes, 2010), denuncia o modo como a gentrificação se legitima a partir do movimento de capital, irregular e flexível, no qual a crescente diferença entre o valor potencial dos imóveis urbanos e os valores subjacentes à terra integra-se ao processo de acumulação de capital.
0 modo como o fenômeno vai se estruturar incialmente seria na década de 1950 e geograficamente limitado (Smith, 2006). Seria categorizado como "gentrificação esporádica" que, precedendo a crise financeira e fiscal, se daria de modo pouco acentuado e com efeitos mais isolados no território urbano - em uma escala local. Utilizando-se de Nova York como cenário de análise, Smith (2006) demonstra que essa gentrificação nascente foi eclipsada por uma migração populacional contínua do centro em direção ao periurbano e pelo fechamento ou deslocamento de empresas obsoletas do distrito central de negócios.

A gentrificação no período de 1950 a 1970 foi esporádica por conta das instituições financeiras que não se mostraram interessadas por investimentos importantes em zonas consideradas "decadentes" - centrais -, somado ao Estado que também não implementou programas de renovação contemplando todo o território da cidade.

Smith (2006) reapresenta uma formulação mais desenvolvida de gentrificação, realizada por Ruth Glass, ${ }^{1}$ a qual considera um processo que se aprimora no final dos anos 1970, quando a invasão de bairros operários londrinos por classes média e alta resulta na mudança substancial na paisagem urbana desses bairros gerada pelo novo status cultural instituído.

Nessa teorização será dada a noção de gentry urbana como famílias de classe média que transformaram os bairros operários em 1964. Nesse momento, o perímetro da cidade é habitado pela burguesia que troca o centro em busca de outra qualidade ambiental - diferente daquela que o centro era capaz de proporcionar, o que vai gerar um cenário de 
redirecionamento do investimento público para as extremidades territoriais da cidade - então "burguesas" - e a consequente degradação das áreas centrais.

Em um argumento constituído desde um ponto de vista da sociologia urbana, Savage, Ward e Warde (2003) ${ }^{2}$ analisam a gentrificação como um fenômeno urbano marcado por uma série de processos de fragmentação espacial e social que o capitalismo é capaz de estruturar, tais como:

- reordenamento do substrato social da cidade onde ocorre a troca nas áreas centrais da cidade, de um grupo social por outro de maior status cultural e/ou econômico;

- formação de núcleos sociais homogêneos quanto ao estilo de vida e características culturais;

- transformação física da paisagem urbana, com a especialização de serviços urbanos e uma reestruturação urbana que prevê importantes melhorias arquitetônicas;

- em decorrência e, ao mesmo tempo, como modo de subsidiar tal transformação, ocorre uma mudança de ordem fundiária que se associa, normalmente, à capitalização do solo urbano e a um incremento nos valores das habitações em propriedade.

Observando os centros urbanos como as áreas onde comumente se estruturam tais processos, Vargas e Castilho (2009) refletem sobre como historicamente essas localidades se tornam potenciais locus da gentrificação como estratégia de políticas públicas para a motivar 0 retorno de investimentos de atores da iniciativa privada. Nessa teia de relações, o centro das cidades passa do local mais dinâmico da vida urbana para um espaço com seus significados erodidos pela expansão urbana e constituição de subcentros, processo que é discutido na
Europa e América desde 1950 e no Brasil apenas a partir de 1980 .

Na medida em que existe uma grande diversidade de funções congregadas ao significado do centro das cidades, a intervenção nessas áreas altera tanto o substrato físico como também a herança histórica e patrimonial.

Quando se observam os projetos de intervenção dos centros urbanos nota-se que grande parte de suas descrições se relaciona à "valorização" do patrimônio histórico. Contudo, como mesmo Smith (2006), Vargas e Castilho (2009), Mendes (2008; 2010) concluem: tais processos têm uma intenção - muito antes da valorização do patrimônio - de enobrecer a imagem da cidade com a reutilização dos edifícios na modernização do comércio, geração de novos empregos e o consequente aquecimento da microeconomia.

Longe de condenar tais iniciativas - já que importam e são positivas em termos de gestão urbana para a manutenção da cidade - esse argumento antes revela a dicotomia da qual participa o fenômeno da gentrificação (Atkinson e Bridge, 2005). 0 que se constata é que existe uma imposição do "emburguesamento de bairros históricos" (Mendes, 2008) sobre os valores simbólicos, patrimoniais e significados que antes conotavam determinados espaços da cidade, o que põe em relevo a face mais negativa da gentrificação:

A gentrificação é, por definição, um processo de 'filtragem social' da cidade. Vem desencadear um processo de recomposição social importante em bairros antigos das cidades, indicando um processo que opera no mercado de habitação, de forma mais vincada e concreta nas habitações em estado de degradação dos bairros tradicionalmente populares. (Mendes, 2010, p. 23) 
A modernização do tecido econômico, assim como a capitalização do solo urbano que dela decorre, se associa diretamente a essas intervenções em que o território é transmutado em mercadoria física e simbólica. Tal mercadoria tem sua difusão no marketing urbano: a exemplo da publicidade que envolveu as olimpíadas de Barcelona promovendo uma completa transformação das suas áreas portuárias deterioradas e abandonadas, tornando-se mundialmente conhecidas e cobiçadas por meio da sua divulgação (Vargas e Castilho, 2006).

Com estratégias similares, Curitiba tem sido projetada como a "imagem da cidade ideal" desde a década de 1970, quando as técnicas do city marketing começaram a ser utilizadas como mecanismo de propagação da cidade com um "planejamento urbano irretocável" e modelo de imagem de uma vida urbana organizada que motivava um certo sentimento de ufanismo local.

As estratégias variam de cidade para cidade, baseando-se na promoção de eventos internacionais ou espetáculos, como nos casos das Olimpíadas de Barcelona, da Expo98 de Lisboa e da Feira de Baltimore, na criação de novos distritos de negócios através da renovação urbana das áreas degradadas. (Nobre, 2010, p. 2)

$\mathrm{Na}$ adoção do planejamento estratégico - advindo do gerenciamento empresarial -, os governos locais inserem o território local em uma competição capital interurbana mundial, fazendo com que as cidades se fixem em circuitos globais, levando algumas de suas características a se globalizar (Smith, 2006). Nesse sentido, os projetos estratégicos endereçados aos centros urbanos se alinham em uma condição de competição entre imagens de cidade, o que coloca em risco a legitimidade das intervenções em relação às características de cada localidade, inclusive das características que fornecem vantagens competitivas que não podem ser reproduzidas.

\section{Da identidade perdida ao espaço enobrecido: o processo de transformação da rua Riachuelo}

A rua Riachuelo foi por aproximadamente três décadas sinônimo de espaço dos marginalizados, prostitutas e usuários de drogas, tendo por muito tempo certo rechaço de apropriação coletiva dado à imagem de espaço abandonado e "mal" frequentado que consolidou ao longo de sua história. Paralelamente tem uma identidade comercial com uma vocação específica para brechós e lojas de móveis usados, o que sempre atraiu grande tráfego de uma população heterogênea em busca de peças históricas e de vestuário com preço e estilo alternativos.

Sendo a primeira via curitibana, ${ }^{3}$ foi também um eixo estratégico de conexão com 0 litoral no século XIX o que, na metade desse mesmo século, motivou a congregação de atividades comerciais e consequente incremento do investimento público (Boschilia, 1996).

Alguns fatos como a inauguração da estrada de ferro em 1885, a proximidade com 0 Mercado Municipal daquele período e a inauguração do Passeio Público em 1886, fortaleceu a capacidade de atração de população local e de serviços para a rua que logo seria cenário da construção de novos hotéis, serviços e comércio administrado por imigrantes (Hoerner, 2002). 
Figura 1 - Obras de colocação dos trilhos dos bondes na rua Riachuelo
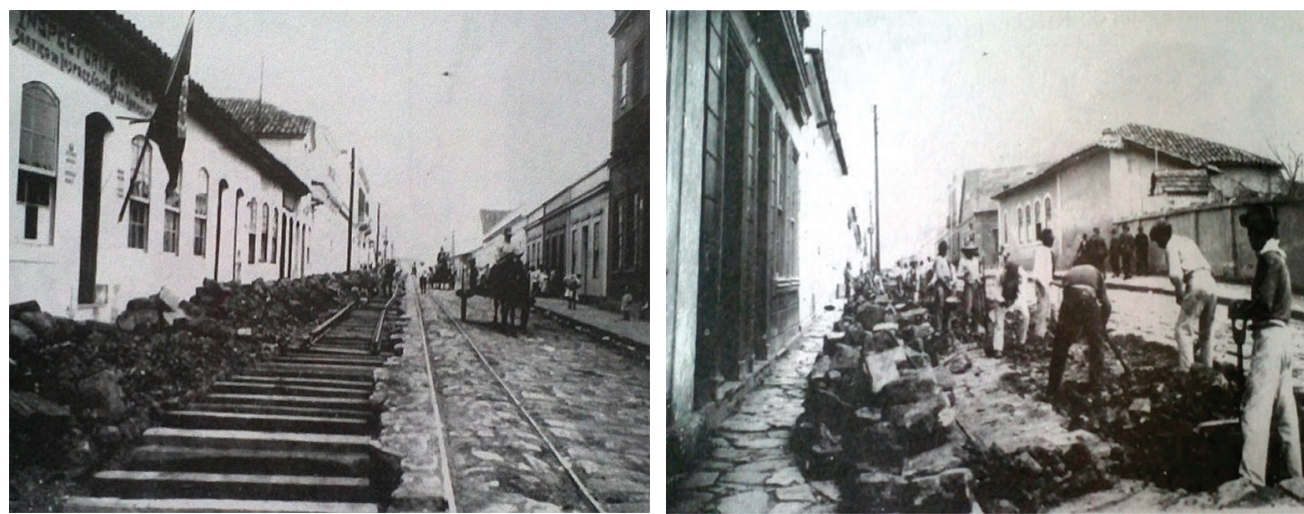

Fonte: Acervo Casa da Memória. Coleção Júlia Wanderley (Boschilia, 1996).

A ascensão da importância da via para a capital não duraria muito. Com infraestrutura para os bondes elétricos que funcionou entre 1913 e final dos anos 1940, a rua passaria por um recesso de investimentos urbanos a partir da década de 1950 especialmente pela troca desse modal de transporte pelos ônibus de linha. A mudança do sistema de transporte público redireciona o foco de investimentos para outros eixos e regiões da cidade, influenciando na degradação da rua Riachuelo que, na década de 1970, já teria sua identidade associada a prostituição e mercado de drogas: "A decadência da região se acentuou nos anos 70 [...], e se agravou há uma década, com o avanço do crack" (Fernandes, 2010).

Paulatinamente, a emigração de sua população moradora para outras regiões valorizadas pela iniciativa da gestão pública faz com que a rua Riachuelo chegue nos anos 1990 com uma alta taxa de vacância dos edifícios residenciais que totalizava $40 \%$ (Sebrae), permanecendo com grande estoque habitacional nos próximos dez anos.

Em toda a década de 1990, Curitiba passou por um período de estruturação de um discurso de valoração da imagem do espaço urbano utilizando-se do marketing. Nesse período, a cidade teve projetos nacionalmente divulgados, tais como Ópera de Arame, Jardim Botânico e rua 24 horas, os quais, junto às soluções de transporte de massa e a programas ambientais, que se tornaram o grande foco das intervenções urbanas e da estratégia de alavancamento da imagem da cidade.

A grande preocupação com a publicidade da "capital ideal" relocou os esforços da gestão urbana para projetos de visibilidade externa, o que faria com que a região central de Curitiba não ocupasse um espaço relevante na pauta das reformas urbanas até meados dos anos 2000. 
Figura 2 - Paço Municipal antes (esquerda) da intervenção e após intervenção
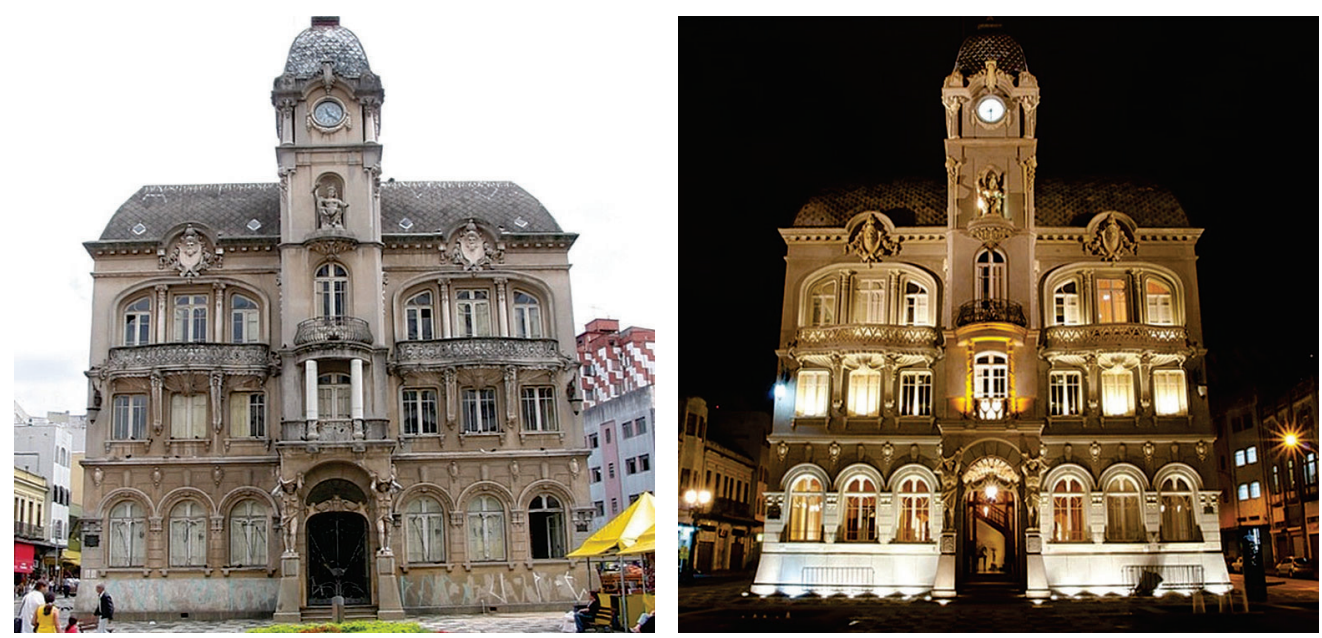

Fonte: Orion do Brasil (s.d.).

Seria em 2008 que a região central da cidade voltaria a receber um horizonte de sua reforma, quando o projeto "Novo Centro" foi lançado. Entre diversas estruturas históricas de relevância patrimonial e vias que organizam 0 funcionamento da cidade, a rua Riachuelo foi contemplada no projeto como uma das primeiras para receber as modificações. Como marco do início da execução do projeto de reforma urbana, o Paço Municipal foi o monumento que teve suas instalações restauradas.

A proposta para a reforma urbana da rua Riachuelo obteve a participação de diversos agentes entre o poder público e o privado, sendo a Fecomércio PR (Federação do Comércio do Paraná) uma das parcerias da prefeitura na empreitada e responsável pelo diagnóstico urbano da região utilizado como base para o desenvolvimento do projeto (Luckman e Romagnolli, 2009, online).

0 argumento inicial da intervenção na rua Riachuelo se pauta em uma "política de valorização" do espaço para a imagem patrimonial da rua e para a manutenção das condições de vida dos moradores e comerciantes locais:

$\mathrm{Na}$ Riachuelo os planos contemplam a reforma das calçadas seguindo o mesmo padrão do entorno do Paço Municipal, decoração e arejamento das esquinas para aumentar a segurança, nova sinalização de trânsito e turística, iluminação privilegiando as calçadas, além da retirada parcial do cabeamento dos postes - segundo 0 arquiteto do Ippuc Mauro Magnabosco, que coordena o projeto do Novo Centro. (Luckman e Romagnolli, 2009, online) 
Figura 3 - Localização da Rua Riachuelo no centro de Curitiba
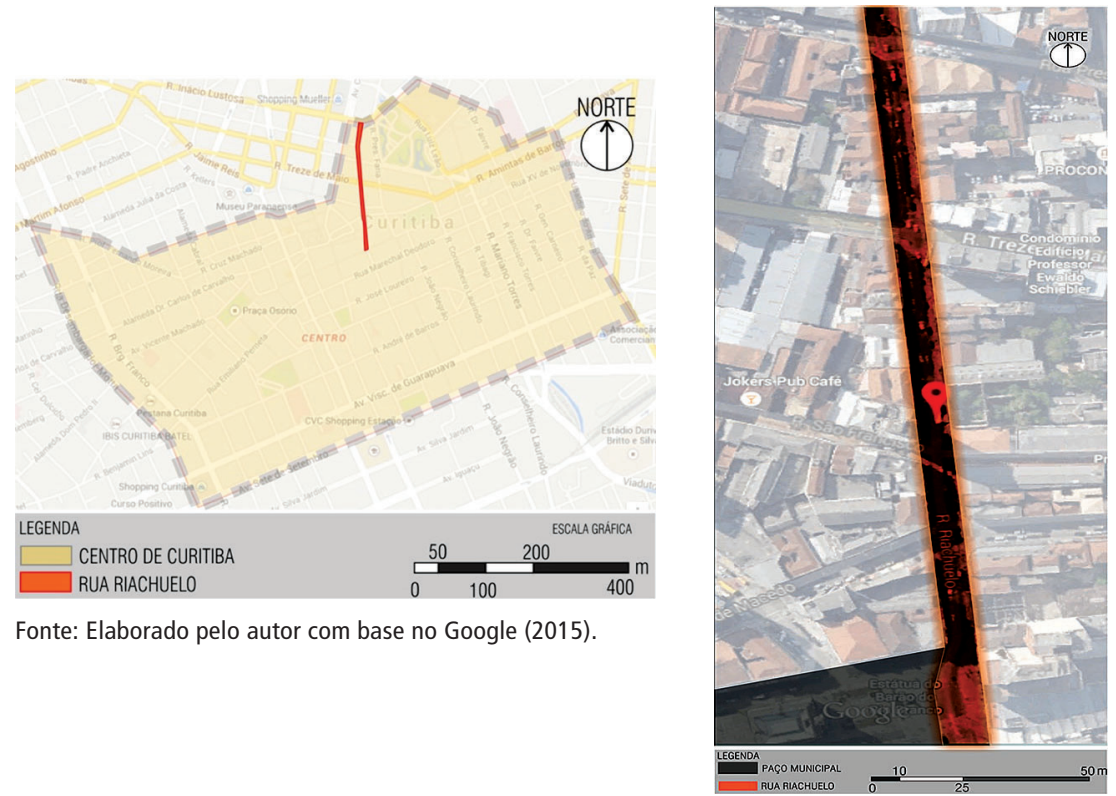

Fonte: Elaborado pelo autor com base no Google (2015).

Figura 4 - Projeto "Nova Rua Riachuelo" - proposta de cores das fachadas

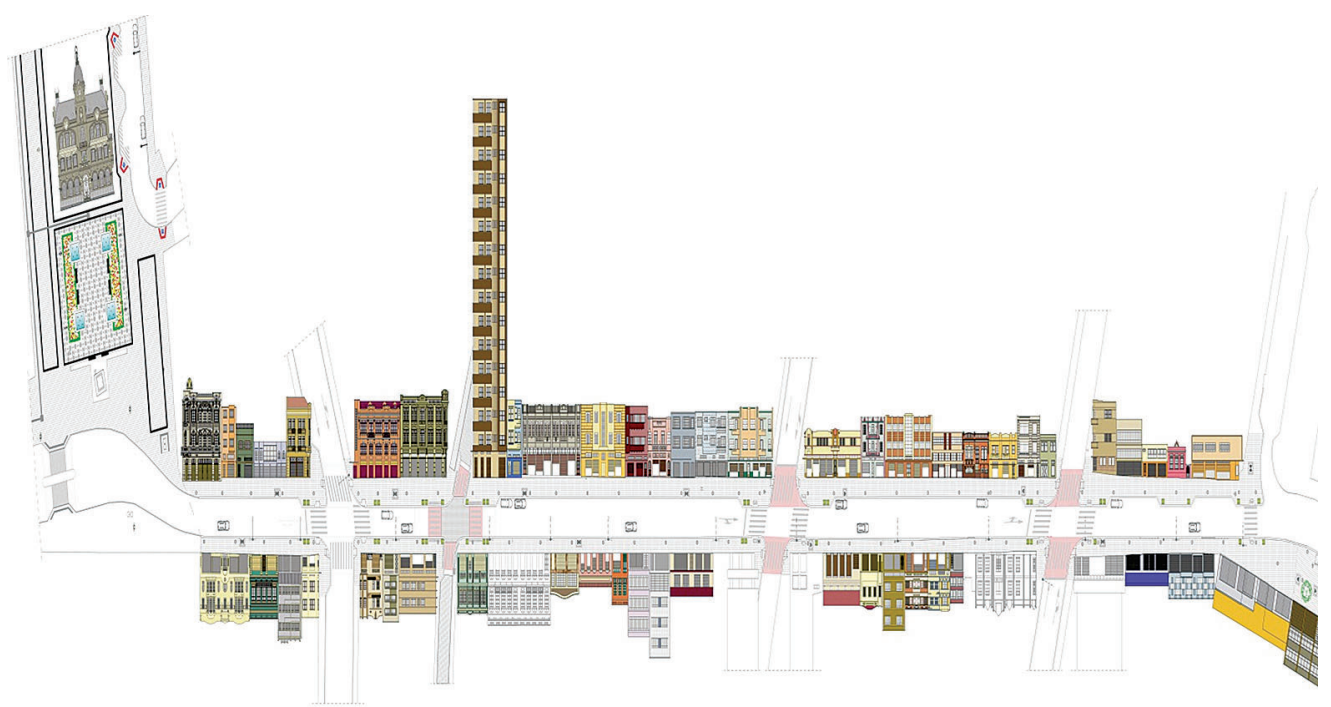

Fonte: Ippuc. Disponível em: http://www.ippuc.org.br 
As fachadas históricas da via receberam nova pintura a partir do projeto do Ippuc (Instituto de Pesquisa e Planejamento Urbano de Curitiba) e da parceria com empresas de tintas: "0 projeto trouxe benefícios como calçadas novas, iluminação, tubulação para dados de telefonia, pintura de fachadas históricas e câmeras de segurança" (Bubniak, 2013, online).

Como estratégia de suporte ao aquecimento da microeconomia local foram ofertadas pela prefeitura consultorias e treinamentos de gestão empresarial em parceria com o Sebrae PR (Nogarolli, 2009). Pouco a pouco a identidade do projeto incorporava em seu slogan um caráter comercial mais evidente: "o projeto pretende revitalizar o deteriorado comércio da região histórica de Curitiba" (Gazeta do Povo, 2009, online, grifo nosso). Percebe-se que, no discurso midiaticamente veiculado, o patrimônio deteriorado tem seu lugar de enfoque na proposta substituído pela preocupação com a deterioração da atividade e capacidade econômica da região: "Eles - 0 Sebrae - vão ajudar os comerciantes da região a transformar sua cultura" (Romagnolli, 2009, online).

Logo, o jornalismo local abriria um importante espaço na agenda de suas notícias para as atividades e processos relacionados à reforma da Riachuelo. Em um dos principais jornais da capital - Gazeta do Povo -, é possível resgatar uma série de publicações em que tanto os títulos das notícias como a "linha-fina"4 expressam o aspecto de reconfiguração da estrutura socioespacial e econômica objetivada pelo projeto.

Declarações presentes nessas entrevistas elucidam como pouco a pouco a Riachuelo foi sendo associada a um produto de marketing urbano, desconstruindo seu sentido simbólico e histórico, tornando o patrimônio um segmento de mercado (Leite, 2002):

As obras que pretendem atrair novos investimentos e moradores para a Riachuelo devem começar na primeira metade de agosto - a prefeitura no momento está fazendo a licitação do projeto estimado em R\$1,5 milhão. (Luckman; Romagnolli, 2009, grifo nosso)

Diego Fillardi, diretor da Thá, diz que a mecânica que viabiliza um empreendimento a partir da conta de aproveitamento do uso do solo aponta condições para produtos de metragens elevadas na região central de Curitiba. "Mas é o poder público, com programas e políticas adequadas, quem fomenta diretamente 0 desenvolvimento das zonas centrais em determinada direção", ressalta. (Moraes, 2013) 


\section{Quadro 1 - Reportagens relativas ao processo de recuperação urbana da Riachuelo ${ }^{5}$}

\begin{tabular}{|l|l|c|}
\hline \multicolumn{1}{|c|}{ Periódico } & \multicolumn{1}{|c|}{ Título e Linha-Fina } & Mês/Ano \\
\hline Gazeta do Povo & $\begin{array}{l}\text { Reportagem: Riachuelo quer recuperar brilho } \\
\text { Linha-fina: Rua do centro histórico de Curitiba passará por obras paisagísticas e recebe } \\
\text { intervenção do Sebrae para voltar a ser um ponto comercial valorizado. }\end{array}$ & $7 / 2009$ \\
\hline Gazeta do Povo & $\begin{array}{l}\text { Reportagem: Lojistas recebem apoio para melhorar atendimento } \\
\text { Linha-fina: Riachuelo tende a ficar mais sofisticada com a atração de novos negócios. Quem } \\
\text { já está ali, tem a chance de dar um salto de qualidade. }\end{array}$ & $7 / 2009$ \\
\hline Gazeta do Povo & Reportagem: Para dar certo ideia pede investimento privado. & $7 / 2009$ \\
\hline Gazeta do Povo & $\begin{array}{l}\text { Reportagem: Projeto prevê transformação da Rua Riachuelo em polo gastronômico } \\
\text { Linha-fina: Plano faz parte do Programa Novo Centro. Objetivo é ampliar o potencial turístico, } \\
\text { revitalizar o comércio da região e melhorar a qualidade de vida dos moradores. }\end{array}$ & $5 / 2009$ \\
\hline Gazeta do Povo & $\begin{array}{l}\text { Reportagem: Rua já passa por valorização } \\
\text { Linha-fina: Antecipando os efeitos do projeto para a Riachuelo, empresários começam a fazer } \\
\text { pequenos investimentos e o custo dos aluguéis da região sobe. }\end{array}$ & $7 / 2009$ \\
\hline Gazeta do Povo & $\begin{array}{l}\text { Reportagem: Revitalizaçães } \\
\text { Linha-fina: Além dos cinemas, outras obras de recuperação do Centro estão previstas dentro } \\
\text { do PAC das Cidades Históricas }\end{array}$ & $6 / 2011$ \\
\hline Gazeta do Povo & $\begin{array}{l}\text { Reportagem: Fôlego novo para o Centro } \\
\text { Linha-fina: Ocupada por moradores de unidades recém entregues, a região precisa de novo } \\
\text { ciclo de habitação, que pode surgir com lançamentos de prédios para famílias. }\end{array}$ & $8 / 2013$ \\
\hline Gazeta do Povos moradores que vão conviver com comércio e população local. & $11 / 2013$ \\
\hline
\end{tabular}

Fonte: elaborado pelo autor (2014).

0 modo como a operacionalização da proposta se encaminha para beneficiar o setor imobiliário ilustra o que Savage, Ward e Warde (2003) argumentam sobre como nesses processos existe uma clara tendência de favorecimento de um estrato populacional específico - normalmente associado a uma camada que detém maior status econômico. A fala do diretor de uma das maiores incorporadoras imobiliárias da capital paranaense ratifica essa constatação.
0 enobrecimento da rua seria fortemente associado a alteração das regulações de uso do solo, onde as políticas permitiriam drásticas modificações quanto às permissividades relativas ao padrão de ocupação da área com importância patrimonial. Grandes torres habitacionais logo começaram a emergir em meio as fachadas históricas utilizando-as, por vezes, como mecanismo de marketing de valorização do empreendimento como ilustrado na Figura 5. 
Figura 5: (A) Fachada antes; (B) Fachada durante a intervenção;

(C) Marketing da incorporadora imobiliária sobre o projeto
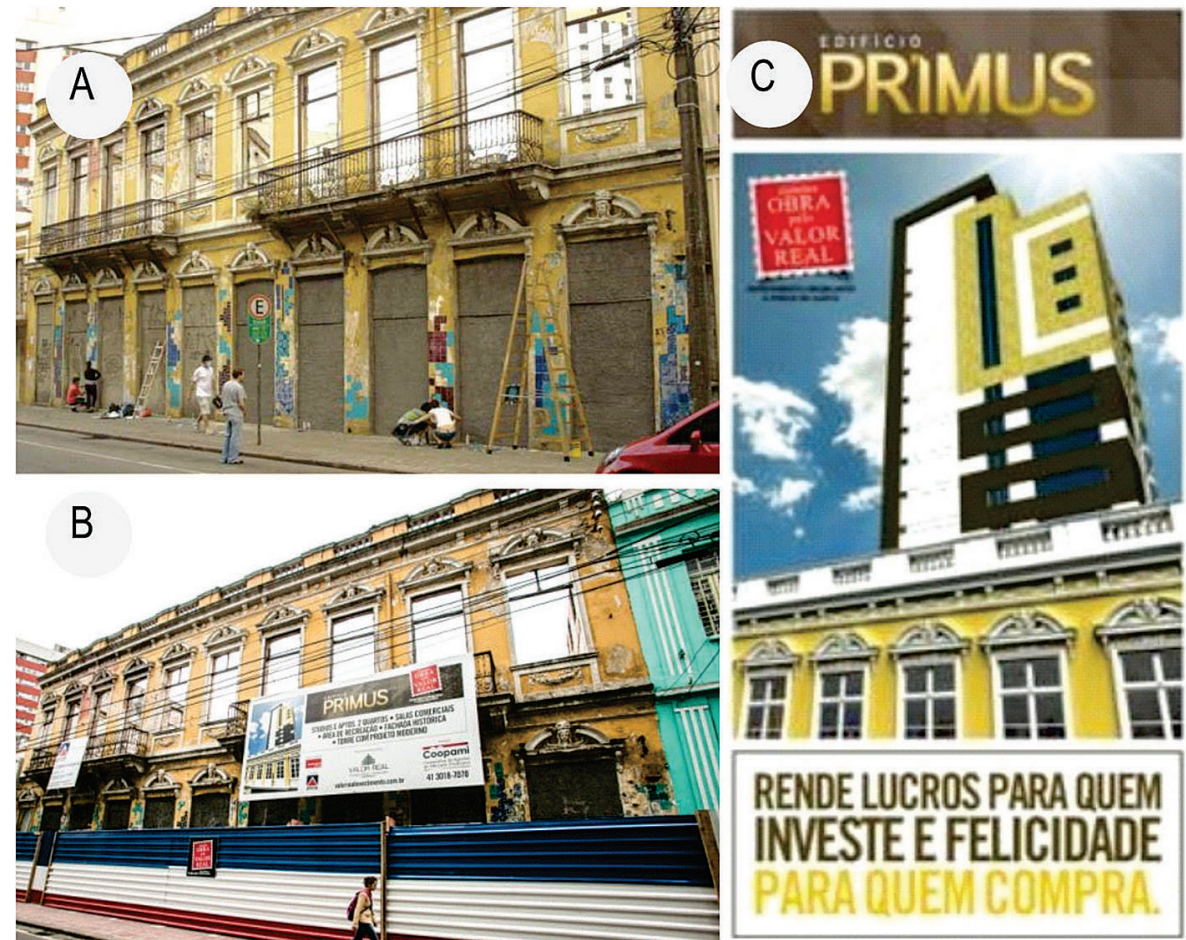

Fonte: Imagens do Google (s.d.).

0 antigo quartel na Riachuelo também foi utilizado para ampliar o potencial construtivo da região histórica. Transformado em Unidade de Interesse Especial de Preservação (UIEP), em um decreto do segundo semestre de 2012, foi previsto o projeto de um novo cinema de rua para a antiga estrutura. Com isso, ficou aberta uma margem de $\mathrm{R} \$ 5$ milhões e 700 mil reais para a venda de potencial construtivo para incorporadoras (Gazeta do Povo, 2012).

A permanência do mercado habitacional como grande articulador do processo, como discutido por Smith (2006), se reflete nas palavras do mesmo diretor da THA quando esse revela como o mercado imobiliário detém conhecimento sobre o alcance da gentrificação, e as possíveis vantagens advindas do processo para o setor: "Diego Filardi, diretor da Thá, observa que em várias cidades do mundo o movimento de revalorização do Centro vem acontecendo em ciclos. 'Estamos atentos a esta tendência mundial e monitorando oportunidades na região' (Moraes, 2013, grifo nosso). 
A empresa em questão publica em sua página web a percepção acerca das movimentações de recuperação da Riachuelo:

0 processo contou com os esforços da Prefeitura Municipal, Sebrae, Sesc, Senac e da Fecomércio que, além de investirem na região, promoveram o incentivo à instalação de novos negócios de acordo com parâmetros estabelecidos para cada um dos eixos [...]. A Riachuelo foi chamada de eixo comercial conceito. (THA, 2011)

Fica claro que o processo de atenuação da segregação socioespacial em áreas endereçadas aos projetos de "regeneração urbana" utilizam o espaço como meio de controle e dominação, privilegiando a livre movimentação de agentes influentes sobre a promoção ideológica da reforma do perfil habitacional, ao invés da reabilitação que normalmente acompanha os discursos iniciais de determinadas propostas (Smith, 2002).

Esse movimento se vê subsidiado também por agentes públicos. No caso específico da Riachuelo, encontram-se diversas declarações de representantes do poder público em favorecimento de tal processo de remodelagem social: "0 projeto para as ruas Riachuelo e São Francisco vai 'domesticar' a região e devolver o conceito de "centro histórico de cidade civilizada". Ainda: " [...]Outra ação esperada para os próximos meses é uma certa 'moralização' da área, onde hoje há um cinema pornô e pontos de prostituição e de tráfico de drogas" (Luckman e Romagnolli, 2009, online - entrevista de Omar Akel - administrador da Regional do setor histórico).

0 caso da Riachuelo remonta ao processo semelhante ocorrido nos bairros e ruas de Recife Antigo, onde "espaços e edificações igualmente importantes em termos patrimoniais se adaptam [...] para adequar as cidades às demandas e aos fluxos internacionais de turismo e consumo urbano (Leite, 2002, online).

Essa "maquilagem estratégica" do caso curitibano traz demais evidências da "marcha" da gentrificação em construção quando demonstrado, em uma perspectiva um tanto hausmanniana, a busca por disciplinar o uso desse espaço público:

0 poder público espera que os empresários tragam atrativos para a região, repovoando o local e gerando riquezas; enquanto os investidores esperam que o governo primeiro "limpe" e valorize a área, para que o risco da aplicação de recursos caia e a taxa de retorno seja parecida com a obtida em outras áreas da cidade. (Luckman, 2009, online "a")

0 modo como o conjunto de ações da recuperação urbana da via se articulou neste curto período (iniciado em 2009) trouxe, logo no início, a preocupação por parte da população local sobre suas possibilidades de permanência desse contexto. Comerciantes entrevistados na época relatavam:
A rua ainda nem foi reformada e os pro- prietários já estão aumentando o valor do aluguel. "Tem imóvel desocupado que já dobrou o preço", informa uma comercian- te instalada no local há 25 anos. "Se a es- peculação aqui descambar [...] vamos ter que fechar as portas". (Luckman, 2009, online "b")

Tais manifestações resgatam as reflexões de Smith (2006) sobre o que ele categoriza como "regeneração urbana" generalizada na qual os impactos da proposta sobre o sítio têm 
efeitos muito mais evidentes no que diz respeito à expulsão camuflada de determinada população, do que uma efetiva recuperação como normalmente nomeada.

A modernização do tecido econômico promovida pelas iniciativas de parceria junto ao Sebrae - e o discurso de aumento de emprego e crescimento econômico logo se fariam perceptíveis na transformação da apropriação e consumo do espaço urbano. No que diz respeito ao uso do solo, o preço do terreno $/ \mathrm{m}^{2}$ mudou substancialmente a partir do projeto na região central. Em 2009, a média dos terrenos estava em torno de $\mathrm{R} \$ 1.400,00 / \mathrm{m}^{2}$, variando $\mathrm{R} \$ 100,00$ a mais no ano seguinte. Em 2011, o mesmo local custava em média $R \$ 2.081,00 / \mathrm{m}^{2}$, chegando em 2013 em $\mathrm{R} \$ 5.000,00 / \mathrm{m}^{2}$ para compra.
0 foco dos empreendimentos imobiliários buscou ressaltar um padrão espacial voltado a moradores jovens que se alinhariam com um novo modo de habitar o centro. A preocupação em fomentar o turismo local por meio dos resultados das intervenções também se faria sensível na transformação da Riachuelo, especialmente porque a imagem de uma rua apropriada tanto localmente como por uma população flutuante afastaria a antiga associação que a rua tinha com uma identidade de abandono: "'A meta é transformar uma área degradada em um grande boulevard gastronômico, com bistrôs, cafés e restaurantes, que dividirão com pontos de cultura os atrativos locais', afirmou o prefeito" (Gazeta do Povo, 2009, online).

Gráfico 1 - Projeção do preço de terrenos $/ \mathrm{m}^{2}$ da região central de Curitiba

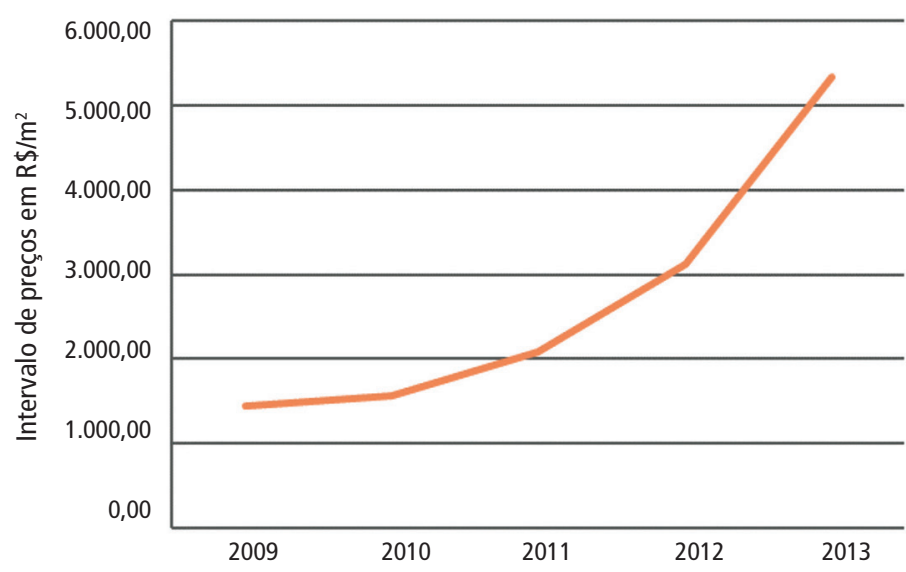
Projeção preço do terreno/m²

Fonte: elaborado pelo autor com base de dados da Inpespar (2014). ${ }^{6}$ 
A veiculação da Riachuelo como um cenário de gentrificação engendrada entre diversos agentes - e não como um fenômeno inesperado - fica evidente entre: 1) as estratégias norteadoras das políticas públicas que agem sobre o projeto; 2) o modo como os atores privados propõem a transformação do cenário socioespacial instrumentalizados pelo poder público; e 3) o teor indutor de respaldo à regeneração urbana presente nos textos midiáticos: "para que a requalificação seja completa, é preciso criar uma nova onda de moradores, apartamentos maiores gerariam um segundo ciclo de moradores e resultados melhores para a cidade" (Moraes, 2013, online).

A exploração da imagem renovada da via alcançaria rapidamente o setor de turismo, que se serviu tanto das transformações da Riachuelo como das obras em geral realizadas a partir do projeto Novo Centro para traçar estratégias de retorno econômico:
- a linha de ônibus Turismo - que funciona desde 1994 passando por 28 pontos turísticos da capital - teve seu itinerário alterado na metade de 2009 para que pudesse passar pela Riachuelo depois da praça Generoso Marques.

- Em 2008, essa mesma linha ônibus tinha um valor de passagem de $\mathrm{R} \$ 16,00$. Em 2013, o preço subiria para $\mathrm{R} \$ 29,00$ ainda com o mesmo itinerário - salvo a inserção da Riachuelo no circuito em 2009 -, o que representa um aumento de $80 \%$ em um intervalo de 5 anos.

As declarações que consideravam a intervenção um "incremento" no perfil social aumentariam:

- "apostamos na repaginação da rua como modo de atrair um comércio mais sofisticado" (Romagnolli, 2009) - Ippuc, Órgão coordenador do projeto;

- nós temos ali um fluxo de pessoas de classe $B, C$, talvez até $D$, que vêm para o centro da

Figura 6 - Perspectivas das propostas Novo Centro (a) Boulevard (b) Novo Cinema
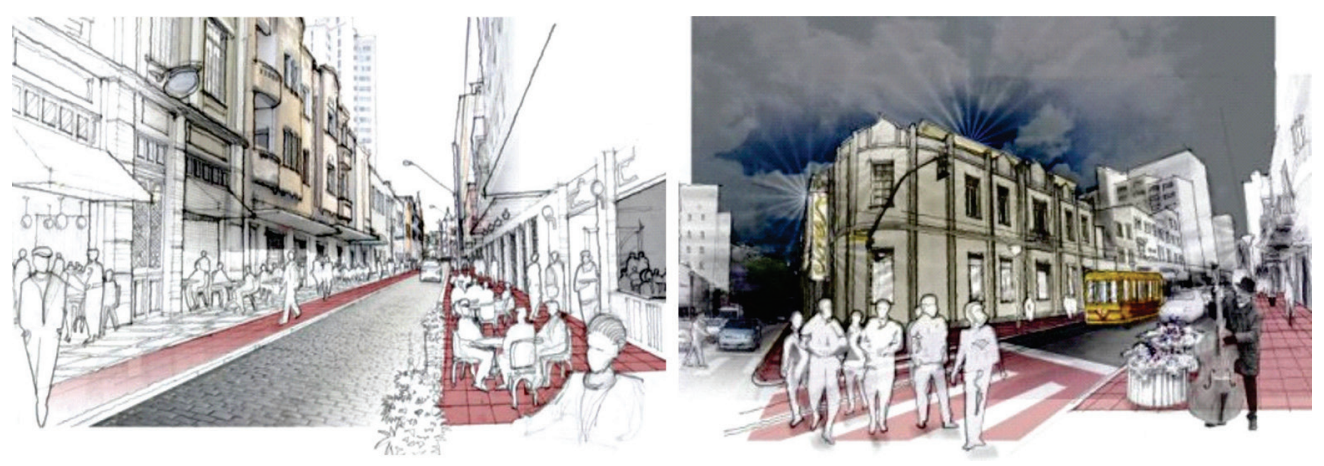

Fonte: Ippuc. Disponível em: http://www.ippuc.org.br. 
Figura 7 - Imagens da rua Riachuelo após intervenção
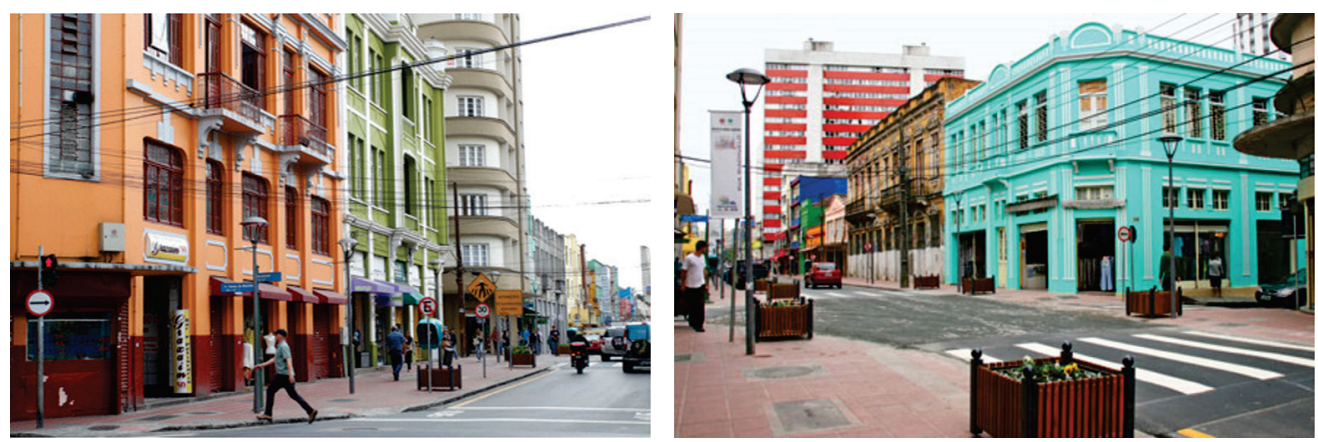

Fonte: Takeuchi (2012).

cidade com recursos muito limitados. 0 comércio vende para esse tipo de freguês, é muito difícil mudar, mas pode ter novos atrativos para buscar um público diferenciado (Romagnolli, 2009, online) - Mauro Magnobosco, Coordenador do projeto.

- "a revitalização da Riachuelo trouxe um perfil diferenciado de cliente, que hoje gasta mais, consumindo produtos no Centro da cidade" (Boletimdopaço, 2011, s.p.) - Sebrae.

Mesmo existindo uma efetiva melhoria (necessária) nas condições de infraestrutura e de paisagem urbana que condicionam a rua Riachuelo, fica claro que nesse processo existe um discurso induzido de "emburguesamento", ou seja, em que a substituição por uma "nova onda" populacional é procurada como modo de ratificar uma apropriação territorial que responda a uma nova ordem econômica, cultural e social. Logo, existe um deslocamento da preocupação com o resgate do valor patrimonial e do significado original do espaço urbano, para outra de buscar a "necessária" substituição social (classicista) que decalca no espaço urbano traços expressivos de diferenciação social.

\section{Da regeneração urbana e seus efeitos sobre o novo cenário da Riachuelo}

A utilização do espaço urbano como arena de aprofundamento de cisões sociais, articuladas em processos de renovação e regeneração urbana (Mendes, 2008), permanece como tendência evidente na extensão do conceito de gentrificação sobre a materialidade. As estratégias engendradas no bojo destas articulações obedecem desenhos políticos das mais diversas ordens, contando com agentes de múltiplos papéis para sua execução.

Curitiba tem uma "preocupação" tradicional com a formulação de sua imagem nas estratégias de gestão, a qual vem sido reforçada desde seu sucesso como "cidade idealmente planejada" na década de 1970. Projetos como o "Novo Centro" vêm retroalimentando determinado aspecto buscando alinhamentos entre poderes público e privado, tendo o respaldo midiático que cumpre importante tarefa de fomentar a apropriação 
populacional da imagem da cidade reinventada, "repaginada".

Contudo, tais estratégias para o caso da rua Riachuelo se fundamentam em uma base de generalização da gentrificação como signo de competição entre cidades pautado em um discurso de inclusão no circuito global (Smith, 2006) o que, em decorrência, coloca-se em contradição com a estrutura social local que sofre drásticas cisões mediadas por esse processo.

Desde os primeiros registros sobre o modo como a gentrificação se engendrou - tendo como arena específica de desenvolvimento o mercado da habitação (Smith, 2006; Mendes, 2012) -, seus limites ampliaram-se para uma expressão sistemática de mudança social e econômica global (Smith, 2006), em especial na cidade contemporânea que se condiciona ao desenho de políticas neoliberais de desenvolvimento urbano nas quais a gentrificação vai conseguir fortalecer-se naturalmente.

Como um fenômeno de manifestação histórica, a gentrificação tem formas de manifestação que se distinguem desde os primeiros episódios pontuais que se localizavam de modo mais restrito nos centros urbanos nos anos 1950. Existe assim, na evolução do fenômeno, uma diferença substancial no que diz respeito tanto às estratégias relativas a sua estruturação como a escala e extensão de seus efeitos socioespaciais e econômicos.

Figura 8 - Esquema teórico da evolução da gentrificação no tempo e espaço

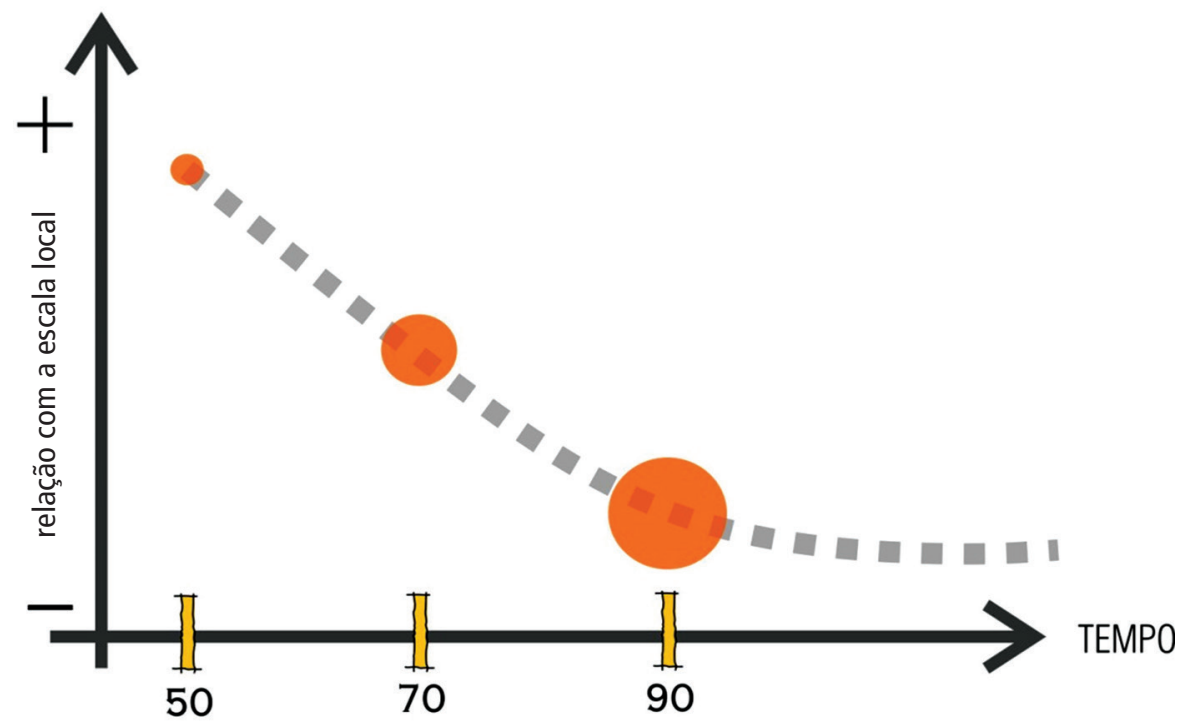

alcance da gentificação : visibilidade e alterações socioeconômicas

objetivos, estratégicas e escalas das intervenções

Fonte: elaborado pelo autor (2015) com base em Smith (2006). 
Desse modo, o movimento espontâneo (e não forjado) de moradores no sentido centro-periferia que, nos anos 1950, associou-se a ações de gestão localizada foi apenas uma fase inicial da gentrificação com impactos bastante isolados. Na cidade contemporânea, o fenômeno atualizou suas formas de difundir-se no espaço urbano por meio de discursos, projetos e ações que se alinham a objetivos de intervenções da imagem da cidade para uma escala territorial ampliada ou até mesmo global.

Nesse processo da busca por imagens competitivas para um circuito global de apropriação, a legitimidade semântica de cada localidade é posta em risco, transformando seus espaços e, em especial os centros históricos, em uma paisagem-mercadoria. Tal dinâmica revela o modo como o espaço urbano tem sido instrumentalizado como meio de ação, controle, dominação e poder para a produção de uma hierarquia dos lugares urbanos pautada na lógica da acumulação.

Existe aí uma dupla face da gentrificação. Por um lado, a recuperação urbana de vazios urbanos, centros históricos ou áreas degradadas - de onde normalmente deriva a manifestação do fenômeno -, é de fato coerente com princípios de gestão que se comprometam com a manutenção das condições socioespaciais e econômicas do espaço urbano. A otimização/ renovação da infraestrutura desses locais - em especial nos centros históricos - implica, em amplo sentido, a manutenção da materialidade e das condições de uso público que ancoram grande parte da memória urbana e constituem a imagem da cidade.

Por outro lado, é fundamental ponderar os alcances do projeto sobre a efetiva recuperação das áreas transformadas e o retorno dos benefícios desse processo para a população moradora. Esse questionamento se coloca na medida em que se observa a tendência de tais intervenções designarem a recomposição social do território alinhando-a com o interesse de inserção da imagem da cidade no mercado turístico internacional, o que motivaria o retorno de investimentos privados interessados na renovação do perfil de consumo do espaço.

Assim, os limites entre a parceria público e privado são tênues, e o modo como as propostas são veiculadas pela mídia merece um estudo com maior cuidado sobre seus resultados. Como bem proposto por Smith, o discurso de regeneração da gentrificação funciona também como um modo de ratificar o poder instituído aos grandes agentes privados envolvidos no processo que, pelas políticas e investimento dos recursos públicos, se veem constantemente favorecidos pela gestão pública, enquanto 0 suporte para a promoção de melhorias efetivas para a vida da população é carenciado nessa articulação (Mendes, 2008).

Em Curitiba, o fenômeno tem se espraiado sem dificuldades em várias porções territoriais da cidade. Uma "nova onda" de definição de identidades para determinadas áreas vem sendo desenhada pela mídia a partir de pesquisas de mercado. Abaixo um trecho de reportagem em que regiões da cidade são anunciadas com estas "novas denominações":

Batel Clássico: Concentra a maior renda média de todas as regiões ( $\mathrm{R} \$ 16 \mathrm{mil}$ ) e 109 estabelecimentos gourmet do total de 231.

Batel Soho: Apesar de pequena, é a região com mais pontos gourmet: 144 , de um total de 431. Em segundo lugar, vem saúde e bem-estar, com 114. Tem 8 mil habitantes por quilômetro quadrado. 
Arte Cívico: A região é pequena, com 113 pontos, mas dinâmica. São 26 gourmet e 36 de saúde e bem-estar. Oito mil pessoas moram na região, que têm renda média de $\mathrm{R} \$ 9$ mil.

Cabral Soho: Tem três mil domicílios, 428 estabelecimentos cadastrados e renda média de $\mathrm{R} \$ 10$ mil. Na região, o segmento forte é o de saúde e bem-estar, com 128 pontos, seguido do gourmet, com 103.

Centro Cultural: São 11 mil habitantes por quilômetro quadrado e 418 pontos no total. 182 estabelecimentos são de moda e na sequência está o gourmet, com 109. Centro Histórico: A região tem 292 estabelecimentos cadastrados, sendo 97 gourmet e 57 moda. A renda média é de $R \$ 7$ mil em mil domicílios.

Jardins: É a região com mais pontos cadastrados. Dos 454, 131 são de saúde e bem-estar e 129, gourmets. A renda média é de $R \$ 9$ mil em um espaço com 5 mil domicílios. (Gazeta do Povo, 2014)

Abaixo o mapeamento proposto na mesma reportagem:

Figura 9 - Mapeamento das identidades comerciais propostas

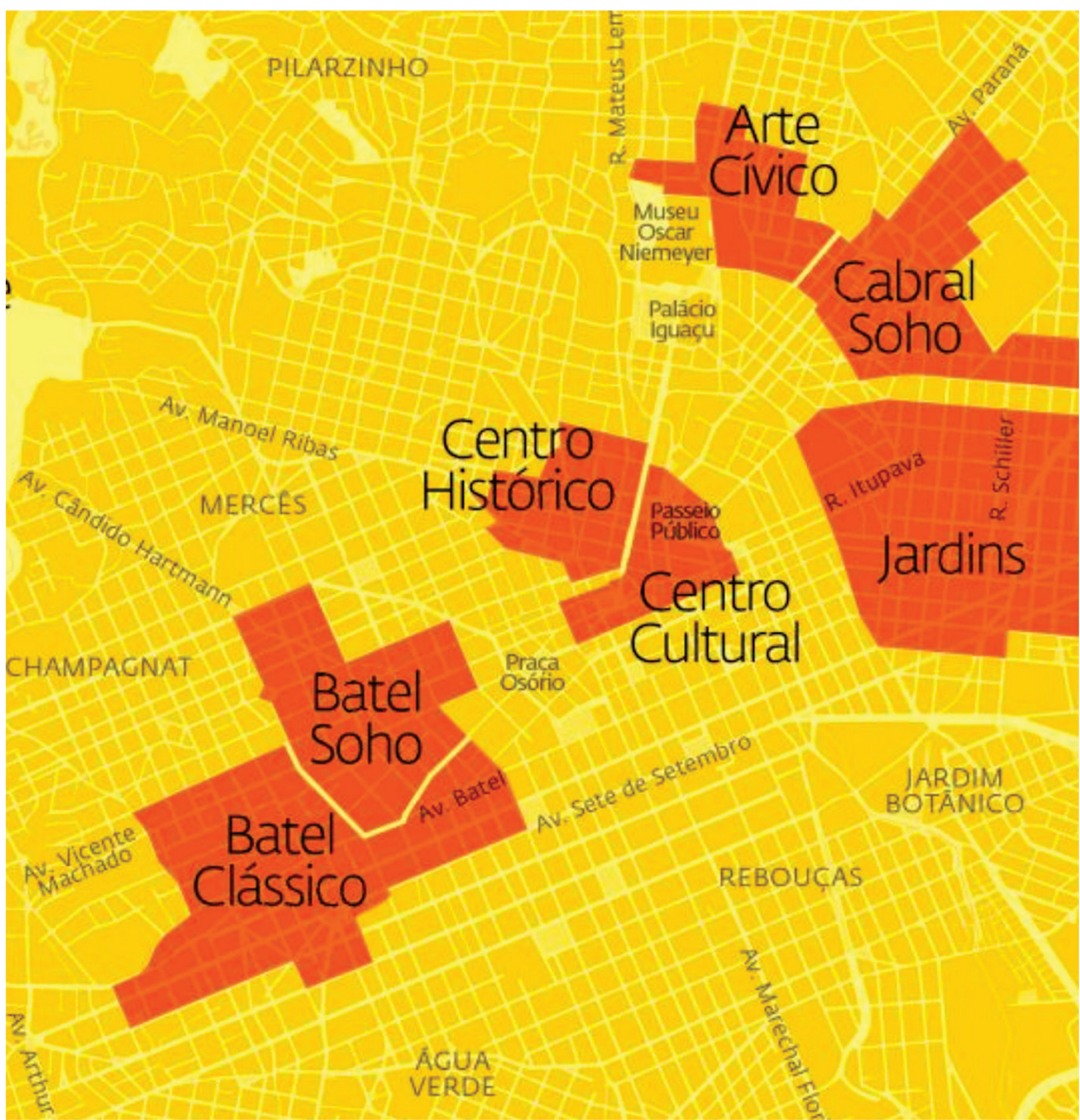

Fonte: Gazeta do Povo (2014). 
No mapa, encontram-se "regiões" como "Jardins", 7 "Batel Soho" e "Cabral Soho". Os nomes sugeridos, em especial os dois últimos, se referenciam a locais gentrificados - como os bairros do Soho em Nova York -, o que expressa a conotação positiva que esse fenômeno ganhou, além de demonstrar o alcance da gentrificação como um produto da globalização (Atkinson e Bridge, 2005).

A rápida evolução do fenômeno em escala e extensão, como anteriormente argumentado, se denota na diferença quanto a sua manifestação inicial que se deu apenas grandes cidades do capitalismo avançado como Londres, Nova York, Paris, etc., e que agora extravasa para uma rede urbana ampla reorganizando sua hierarquia, o que é um dos pontos de principal distinção da manifestação da gentrificação dos anos 1950 aos 1970 para os processos atuais.

No caso da rua Riachuelo, seus resultados já são expressivos. 0 aumento exponencial do preço do solo, a priorização de uma "nova onda" populacional pelos atores, a transformação da paisagem em mercadoria turística, 0 controle do espaço público, a mudança dos padrões de zoneamento assim como as propostas de polo gastronômico, ou do Boulevard, representam efeitos já sensíveis à população local e remontam à teorização de Smith (2006) e de Savage, Warde e Ward (2003).

Como as obras estão em andamento, inclusive as relativas aos empreendimentos residenciais, não se sabe ao certo o alcance que terão as mudanças geradas pelas propostas para a rua Riachuelo. Contudo e, em última análise, é evidente que o modo como se deram as tratativas e os encaminhamentos da proposta para essa via beneficiou os agentes imobiliários e as empresas, os quais puderam explorar a mais-valia do solo a partir das alterações dos padrões de ocupação urbana que a área sofreu. No que tange à gentrificação da região, esse processo paralelamente parece induzir a substituição paulatina dos residentes locais e, em especial, dos comerciantes que pelo discurso ideológico de "valorização" e regeneração possivelmente não alcançarão as condições de manutenção de vida nesse cenário de enobrecimento premeditado.

\section{Andrei Mikhail Zaiatz Crestani}

Pontifícia Universidade Católica do Paraná, Escola de Arquitetura e Design, Faculdade de Arquitetura e Urbanismo. Curitiba/PR, Brasil andreizaiatz@gmail.com 


\section{Notas}

(1) Glass foi uma socióloga britânica que em 1964 utilizou o termo "gentrificação" para se referir a alterações que ela observava na estrutura social e do mercado de habitações em certas áreas no centro de Londres.

(2) Em especial no capítulo 4: "Desigualdade e organização social na cidade".

(3) A rua Riachuelo recebeu vários nomes antes do atual: rua Lisboa, rua dos Veados, rua do Campo e rua da Carioca.

(4) Pequeno texto geralmente logo abaixo do título da reportagem: um subtítulo que estende a explicação do título.

(5) O Quadro 1 é composto apenas de algumas reportagens relacionadas à intervenção da Riachuelo encontradas durante a pesquisa.

(6) Os valores relacionados aos anos de 2012 e 2013 foram levantados pelo autor a partir da média dos terrenos anunciados nesses períodos na região. Os valores de 2009, 2010 e 2011 foram fornecidos pelo Inpespar (Instituto Paranaense de Pesquisa e Desenvolvimento do Mercado Imobiliário e Condominial).

(7) Referência ao nome da região nobre de São Paulo?

\section{Referências}

ATKINSON, R. e BRIDGE, G. (2005). Gentrification in a global context: the new urban colonialism. Routledge, Nova York.

BIDOU ZACHARIASEN, C. (2006). "Introdução". De volta à cidade: dos processos de gentrificação às políticas de "revitalização" dos centros urbanos. São Paulo, Annablume.

BOLETIM PAÇO DA LIBERDADE (2010). Siga as cores da revitalização, abril, v. 3, n. 11. Disponível em: http://app.pr.sebrae.com.br/FCKeditor/userfiles/file/PORTAL\%20COMERCIO\%20VAREJISTA/ PACO\%20MUNICIPAL/Boletim\%2011.pdf. Acesso em: 27 dez 2013.

(2011). Inovação. Setembro, v. 4, n. 23. Disponível em: http://app.pr.sebrae.com.br/FCKeditor/ userfiles/file/boletim23set_pdf.pdf. Acesso em: 27 dez 2013.

BOSCHILIA, R. (1996). Cores da cidade: Riachuelo e Generoso Marques. Curitiba, Fundação Cultural de Curitiba, v. 23, n. 110, mar.

BUBNIAK, T. (2013). Mistura boa no centro. Gazeta do Povo, nov. Disponível em: http://www. gazetadopovo.com.br/imobiliario/conteudo. phtml?id=1427566\&tit=Mistura-boa-no-centro. Acesso em: 27 dez 2013.

FERNANDES, J. C. (2010). Riachuelo 407. Gazeta do Povo, setembro. Disponível em: <gazetadopovo. com.br/vidaecidadania/conteudo.phtml?id=1026175\&tit=Riachuelo-407> Acesso em: dez 2013. 
GAZETA DO POVO (2009). Prefeitura publica edital para revitalização das calçadas da Riachuelo. 17 de julho. Disponível em: http://www.gazetadopovo.com.br/vidaecidadania/conteudo. phtml?id=906336. Acesso em: $27 \mathrm{dez} 2013$.

(2012). Antigo quartel abrigará Cine Passeio. 19 de setembro. Disponível em: http://www. gazetadopovo.com.br/cadernog/conteudo. phtml?tl=1\&id=1298690\&tit=Antigo-quartelabrigara-Cine-Passeio. Acesso em: 27 dez 2013.

(2014). Geocook: identificar, destacar e estimular a gastronomia. 9 de janeiro. Disponível em: http://www.gazetadopovo.com.br/bomgourmet/identificar-destacar-e-estimular/. Acesso em: 12 jan 2014.

GLASS, R. (1964). London: aspects of change. Londres, Centre for Urban Studies and MacGibbon and Kee.

HAMNETT, C. (2003). Gentrification and the Middle-Class Remaking of Inner London: 1961-2001. Urban Studies, v. 40, n. 12, pp. 2401-2426. Disponível em: http://usj.sagepub.com/content/40/12/2401. full.pdf. Acesso em: 20 dez 2013.

HARVEY, D. (1989). The condition of postmodernity: an enquiry into the origins of cultural change. Oxford, Blackwell Publishers.

HOERNER Jr., V. (2002). Ruas e Histórias de Curitiba. Curitiba, Artes \& Textos.

IPPUC. Imagem do Projeto pintura das fachadas da rua Riachuelo. Disponível em: http://www.ippuc. org.br/visualizarfoto.php?doc=http://admsite.ippuc.org.br/arquivos/fotos/F117/F117_006_ BR.jpg. Acesso em: 4 jan 2014.

LEITE, R. P. (2002). Contra-usos e espaço público: notas sobre a construção social dos lugares na Manguetown. Revista brasileira de Ciências Sociais [online], v. 17, n. 49, pp. 115-134. Disponível em: scielo.br/scielo.php?script=sci_arttext\&pid=S0102-69092002000200008. Acesso em: set 2012.

LUCKMAN, A. (2009a). Para dar certo, ideia pede investimento privado. Gazeta do Povo, julho. Disponível em: http://www.gazetadopovo.com.br/economia/conteudo.phtml?tl=1\&id=906645\&tit=Paradar-certo-ideia-pede-investimento-privado. Acesso em: 27 dez 2013.

(2009b). Rua já passa por valorização. Gazeta do Povo, julho. Disponível em: http://www. gazetadopovo.com.br/economia/conteudo.phtml?tl=1\&id=906639\&tit=Rua-ja-passa-porvalorizacao. Acesso em: $27 \mathrm{dez} 2013$.

LUCKMAN, A. e ROMAGNOLLI, L. (2009). Riachuelo quer recuperar brilho. Gazeta do Povo, setembro. Disponível em: gazetadopovo.com.br/economia/conteudo.phtml?tl=1\&id=906635\&tit=Riachue lo-quer-recuperar-brilho. Acesso em: 27 dez 2013.

MENDES, L. (2008). Gentrificação e a Cidade Revanchista: que lugar para os Movimentos Sociais Urbanos de Resistencia? Forum Sociológico, n. 18, pp. 21-28.

(2010). O Contributo de Neil Smith. e-metropolis: Revista eletrônica de estudos urbanos e regionais, v. 1, n. 1, pp. 21-33.

MORAES, B. (2013). Fôlego novo para o Centro. Gazeta do Povo, dezembro. Disponível em: http://www.gazetadopovo.com.br/economia/perfilimobiliario/conteudo. phtml?tl=1\&id=1430380\&tit=Folego-novo-para-o-Centro\#ancora. Acesso em: 27 dez 2013. 
NOBRE, E. (2003). Intervenções urbanas em Salvador: turismo e "gentrificação" no processo de renovação urbana do Pelourinho. In: X ENCONTRO NACIONAL DA ANPUR, Belo Horizonte, maio. Disponível em: <fau.usp.br/docentes/depprojeto/e_nobre/intervencoes_urbanas_Salvador. pdf> Acesso em: 7 set 2013.

NOGAROLI, A. de F. (2009). Revitalizar é compreender o valor. Boletim Paço da Liberdade, n. 6, jul. Disponível em: http://app.pr.sebrae.com.br/FCKeditor/userfiles/file/Varejo/BOL006.pdf. Acesso em: 18 dez 2013.

ORION DO BRASIL. Imagens do Paço Municipal antes da intervenção e após intervenção. Disponível em: http://www.oriondobrasil.com.br/portfolio/paco-municipal-de-curitiba/. Acesso em: 10 jan 2014.

PARKINSON, M. e JUDD, D. (1990). Leadership and urban regeneration. Newburry Park, Sage Publications.

ROBINSON, F. (1989). Urban Regeneration Policies in Britain in the late 1980s: Who Benefits? Centre for Urban and Regional Development Studies. New Castle Upon Tyne, University of New Castle Upon Tyne.

ROMAGNOLLI, L. (2009). Lojistas recebem apoio para melhorar atendimento. Gazeta do Povo, julho. Disponível em: http://www.gazetadopovo.com.br/economia/conteudo.phtml?tl=1\&id=906641 \&tit=Lojistas-recebem-apoio-para-melhorar-atendimento. Acesso em: 27 dez 2013.

SAVAGE, M; WARDE, A. e WARD, K. (2003). Urban sociology, capitalism and modernity. Hampshire, Palgrave.

SMITH, N. (2002). New globalism, new urbanism: gentrification as global urban strategy. Antipode, v. 34, n. 3, pp. $427-450$.

(2006). "A gentrificação generalizada: de uma anomalia local à "regeneração" urbana como estratégia urbana global". In: BIDOU-ZACHARIASEN, C. (ed.). De volta à cidade: dos processos de gentrificação às políticas de "revitalização" dos centros urbanos. São Paulo, Annablume.

TAKEUCHI, W. (2012). Imagens da rua Riachuelo após intervenção. Disponível em: http://www. circulandoporcuritiba.com.br/2012/09/caminhando-pela-riachuelo-1.html. Acesso em: 8 jan 2013.

THA (2011). A Rua Riachuelo e o Paço da Liberdade. Assessoria de Imprensa construtora THA, set. Disponível em: http://www.tha.com.br/espacotha/regioes-em-destaque-a-rua-riachuelo-e-opaco-da-liberdade/. Acesso em: 3 jan 2014.

VARGAS, H. C. e CASTILHO, A. L. H. (2009). Intervenções em centros urbanos: objetivos, estratégias e resultados. Barueri, Manole.

Texto recebido em 13/jan/2014

Texto aprovado em 16/out/2014 